\title{
Perceptions and Realities in Assessment Definitions and Uses
}

\author{
Maddalena Taras \\ University of Sunderland, Faculty of Education and Society \\ Sunderland SR1 3SD, UK
}

Tel: 44-191-515-2910. E-mail: maddalena.taras@sunderland.ac.uk

Mark S. Davies (Corresponding author)

University of Sunderland, Faculty of Applied Sciences

Sunderland, SR1 3SD, UK

Tel: 44-191-515-2517. E-mail: mark.davies@sunderland.ac.uk

\author{
Received: July 30, 2013 Accepted: November 22, 2013 Published: January 12, 2014 \\ doi:10.5296/ijssr.v2i1.4065 URL: http://dx.doi.org/10.5296/ijssr.v2i1.4065
}

\begin{abstract}
Assessment has an ambiguous position in education particularly with regards to learning and teaching. While taking the role of both the carrot and the stick it has an uneasy truce as an unwelcomed necessity and the source of problems for both tutors and learners. It ratifies the existence of institutions and oversees everything we do. We surveyed 51 university lecturers in science to determine their understandings of definitions of assessment and uses to which these are put. The plausibility of finding rational and coherent understandings was questioned, given that recent theoretical models and discourses tend not to be alligned. The results confirmed this belief indicating considerable disparity and inconsistencies. Understanding assessment definitions and uses must be one of the basic requirements of something so central to everything we do, yet this study demonstrates that we are far from being clear about our understandings of assessment and how and why we use it.
\end{abstract}

Key words: assessment, definition, formative, science, summative, theory, practice 


\section{Introduction}

Assessment processes and practices increasingly control educational frameworks and are a determining factor impacting on perceptions and satisfactions of learning and teaching as, to take just two examples, the Course Experience Questionnaire (Australia) and the National Student Survey (UK), testify (Yorke, 2013). In addition to the impact on learners, assessment also controls tutors', institutions' and government agencies' activities and understandings of education in increasingly subtle and pervasive ways (Knight, 2002; Broadfoot \& Black, 2004). Therefore, given the centrality of assessment to education at all levels, any research that can lead to clarification of our understandings of assessment is of great importance to the academic community.

With learner and learning-centred discourse much progress has been made on aligning learning and teaching practices and empirical research. Less evident and extensive is the aligning of assessment theories, practices and research with learning and teaching (Rust, 2002). Although there is a long-standing tradition of work supporting and researching student-inclusive assessment (e.g. Cowan, 2006; Smith \& Sodano, 2011; Lindblom-Ylänne ett al., 2006), it is still a moot point whether students are really a part of the assessment community of practice in higher education.

The education communities' wish to use assessment in the support of learning and teaching as opposed to solely focusing on functions of accreditation and validation has led to a dichotomy between summative and formative assessment (Scriven, 1967; Sadler, 1989; Black \& Wiliam, 1998, 2009). This has led to definitions and uses of both of these being understood differentially (Taras, 2009; Taras \& Davies, 2013).

The literature on assessment is extensive; the vast majority, both within the compulsory and post-compulsory sectors concerns a wide range of contextually different scenarios of practice and empirical research. Although there is an on-going set of theoretical discussions linking formative and summative principles, processes, practices and functions there is a paucity of research that examines and clarifies current understandings in practitioners (McLellan, 2001; Hargreaves, 2005).

Here we focus on university lecturers' understanding of the definition of summative and formative assessments (SA and FA), the relationship between them, and related tasks and contextualisations (Hargreaves, 2005; Stobart, 2008). SA and FA have become ubiquitous in all discourses of learning, teaching and assessment, and yet very little research has been done to untangle different understandings. This research aims to address this gap. Here we canvassed the opinions of science lecturers: since science education and training places strong emphasis on logic and the critical evaluation of evidence, we posited that there would be a high degree of homogeneity across responses to questions asking for a theoretical viewpoint. As far as we are aware there has been little focus on this group, although Taras and Davies (2013) investigated its understandings of functions and processes of assessment. 


\subsection{Assessment of and for Learning}

Despite the differences across sectors, much of the literature (e.g. Nicol \& Macfarlane-Dick, 2005; Wiliam, 2007; Black \& Wiliam, 2009) uses Sadler's (1989) theory of FA as a common baseline. This theory focuses on three aspects: the importance of using feedback to improve work; the necessity of using self-assessment by students in order for the parameters of assessment to be understood and for feedback to be used and therefore to ensure that FA has taken place; and for criteria to be a constant point of discussion as they are in constant flux during assessment.

Another author and his work on assessment is also quoted regularly, Scriven (1967), but in the case of Scriven, the interpretation and reading of his work is not consistent (Harlen, 2006; Wiliam, 2007, 2009; Black \& Wiliam, 2009; Taras, 2009). Taras focuses on the process of assessment and how all assessment uses parameters (that is, criteria, standards, outcomes, etc.) either explicitly or implicitly to form a judgement. This judgement is a summation at any given point in time, which if it produces feedback that is used to improve work in learning, becomes FA as stated by Sadler. Black \& Wiliam, on the other hand, maintain their focus on functions of assessment and on the irreconcilable separation of summative and formative functions, although in recent work it is no longer the function but the actual use to which the assessment is put that is important. Although assessment discourses have examined SA and FA extensively, it is astonishing that little recent work has focused on the processes of assessment and the relationship between central terminologies.

A further consequence of the lack of engagement with the clarification of the relationships between SA and FA functions and processes, and how these relate to feedback, learning, peer and self-assessment (McLellan, 2001; Hargreaves, 2005), is that the education community is drip-fed disparate and fragmented discourses which remain fragmented and unrelated. It may be that although many pockets of good practice would continue across the education community, and dissemination and take-up of these would help sustain excellence in learning and teaching, disparate understandings of assessments would result in a flawed and incomplete picture where pockets of beliefs replace a coherent and complete theoretical picture. Since we are limited by the theoretical frameworks available, if these are limited, flawed and incomplete, this will inevitably be reflected in our understandings.

\section{Research Method}

A questionnaire of 18 questions was distributed to 51 lecturers in a variety of health and life science-related academic teams in a science faculty at an English university in 2010 (Appendix 1). It was not possible to distribute the questionnaire to all participants at the same time and so it was issued on an opportunistic basis over a period of 8 months on occasions when each academic team met to discuss business. Lecturers were told that the questionnaire was to be completed anonymously and were instructed to answer the questions in order and not to go back. They were asked not to confer but told that they could ask for clarification of any question. Six lecturers were observed to scan the entire questionnaire before completing it. Six asked the meaning of 'conflate' which was roughly given as 'carry out at the same time'. Questionnaires were collected immediately on completion; no participant took more than 


\section{MInstitute Macrothink $_{\text {Int }}$}

fifteen minutes to complete the questionnaire. This questionnaire had been validated during an earlier study (Taras, 2008a).

For many questions a yes/no response was required and data were analysed accordingly. However, some questions were qualitative in that they required a written comment. Questions asked for: a rough definition of firstly SA and then FA; examples of SA and FA tasks; an example if summative and formative tasks are conflated; how formative work is related to summative work; and the final questions asked again for definitions of SA and FA. We asked twice for definitions to examine the impact of completing the questionnaire on participants' thinking. We have termed the initial definitions asked for as 'first definitions' and those asked for at the end of the questionnaire as 'second definitions'. These questions required analysis and interpretation before quantifying. Key words were selected and analysed (a "semantic" interpretation or interpretation based on the literal meaning of the word(s) in question) to find the general trends that appeared from repetition of words and ideas and the responses were classified. In addition, where possible the distinctions between assessment "of" learning, "for" learning or both were made: the latter was an additional analysis over the 2008a paper.

It was not possible to compare results between academic teams or between any demographic indicators because the sample sizes were too small; in any case academic teams were not strictly differentiated by discipline and there was long-term movement of academic staff between teams.

One questionnaire was excluded from the sample due to a lack of engagement in supplying data. Therefore the total number of questionnaires used was 50. The fractions quoted in the results section are based on the number of responses to each question. Since the number of respondents was not always the same the denominator may vary.

\section{Results}

It is worth describing the single case where there was a lack of engagement. In response to the questions asking for rough definitions of SA and FA, "not sure" was written; "can't" was the response to questions asking for examples. For questions asking for a yes/no response 'no' was indicated in all cases. When asked for an example of conflated summative and formative tasks the response was “can't - don't honestly know what formative and summative mean! Sounds like jargon". In answer to the final two questions asking again for definitions of SA and FA, the responses were both "can't - don't know what it is".

\subsection{First Definition of Summative Assessment}

\subsubsection{Semantic Analysis}

$46 \%(23 / 49)$ of respondents used the words "mark", "grade" or "score" to describe SA. In addition "end" or "final" were words used by $42 \%(21 / 49)$ of respondents, linking the words to the end of course work. However, only $10 \%(5 / 50)$ used both the ideas of grade and final. "Formal" was used by 6\% (3/49). Some replies, 16\% (8/49), go against the general trend of formal, final graded work and used words such as "informal", "no grade", and "learning": 4\% (2/49) used the phrase "assessment for learning" as a definition of SA. 


\subsection{2 "of" or "for" Learning}

$82 \%$ (41/49) of respondents gave an answer classified as "of" learning, $10 \%(5 / 49)$ gave an answer classified as "for" learning, and $8 \%$ (4/49) of respondents' answers were classified as both. Of the remainder, $2 \%$ (1/49) were not sure, $2 \%$ (1/49) were "unclear" and 2\% (1/49) were difficult to classify as the respondent stated "Assessment throughout the module".

\subsection{Second Definition of Summative Assessment}

\subsubsection{Semantic Analysis}

$42 \%$ (21/47) mentioned the contribution of marks to an overall score, $40 \%$ (20/47) mentioned "final" or "end", $10 \%(5 / 51)$ included the issuing of feedback to students, and one used the word "formal" and one the phrase "continually tests learning". Four indicated that their response had not changed from that given previously to this question. More unusual responses were "assesses product and process but included in the final marks", "assesses the learning process", "presentation on an assigned topic designed to assess students' knowledge base before formative assessment", "assesses product used for validation" and "it provides summative feedback to students (assesses learning)".

\subsection{2 "of” or "for” Learning}

$76 \%(38 / 47)$ gave an answer classified as 'of learning', 6\% (3/47) 'for learning', and 10\% (5/47) both. One answer could not be classified and was "assessing the learning process".

\subsection{First Definition of Formative Assessment}

\subsubsection{Semantic Analysis}

$34 \%(17 / 48)$ used the word "feedback" in their answer, referring to feedback given by staff to students on their performance. A small proportion $(4 \%, 2 / 48)$ of respondents equated FA with "feedback" or "giving feedback on a piece of work". One described FA as summative "but less rigorous". Two saw it as an opportunity to give feedback on drafts of work to be later submitted for SA.

\subsection{2 "of” or "for” Learning}

$50 \%(25 / 48)$ of respondents gave an answer classified as "for" learning, 38\% (19/48) gave an answer classified as "of" learning, and $8 \%(4 / 48)$ of respondents' answers were classified as both. Of the 25 classified as answering "for" learning, only three used that phrase explicitly. Three did not provide a classifiable response.

\subsection{Second Definition of Formative Assessment}

\subsubsection{Semantic Analysis}

$34 \%(17 / 47)$ mentioned "feedback", and 6\% (3/47) clearly indicated that FA precedes or leads to SA. 8\% (4/48) of respondents equated FA with "feedback". One responded "assesses product used for learning", one "assesses product and process", one "assesses validation", and one "to provide a view on overall teaching and learning". One equated FA with SA, "but less 


\section{Macrothink}

rigorous in setting".

\subsection{2 "of" or "for" Learning}

$44 \%(22 / 47)$ of responses were classified as "for" learning, 4\% (2/47) used the phrase "for learning"), $30 \%$ (15/47) were classified as "of" learning, and 14\% (7/47) were classified as both. $10 \%(5 / 47)$ simply referred back to the answer given for the first definition. Three responses were unclassifiable: "prepare for assessment", "using current knowledge to form answers to new problems", and "no exam".

\subsection{Consistency of Definition Responses (Table 1)}

In response to the two questions that asked for a definition of SA, 34/50 (68\%) respondents gave answers consistently classified as "of" learning, 3/50 (6\%) were consistently classified as "for" learning and 1/50 (2\%) was consistently classified as both. One was consistently not sure. If we exclude the cases where no response was given ('blank' in Table 1) on the grounds that these might have arisen from an unwillingness to participate, 9/50 (18\%) participants gave answers classified differently between the first and second asking of the question. 2/50 (4\%) moved from "for" learning to "of" learning and none vice versa.

Table 1. The consistency of classified responses to the repeated questions asking for definitions of SA (questions 1 and 17) and FA (questions 3 and 18). Numbers refer to frequency of responses that were classified according to the scheme in columns 1 and 2 ("for" learning (for), "of" learning (of), both, unscorable, "not sure" and left blank). Only recorded permutations given

\begin{tabular}{llll}
\hline $\begin{array}{l}\text { Classified response to } \\
\text { question } 1 \text { or } 3\end{array}$ & $\begin{array}{l}\text { Classified response to } \\
\text { question } 17 \text { or } 18\end{array}$ & $\begin{array}{l}\text { Frequency for } \\
\text { definitions of SA }\end{array}$ & $\begin{array}{l}\text { Frequency for } \\
\text { definitions of FA }\end{array}$ \\
\hline of & of & 34 & 12 \\
for & for & 3 & 20 \\
both & both & 1 & 3 \\
of & for & 2 & 2 \\
for & of & 4 & 1 \\
of & both & & 2 \\
for & both & 1 & 2 \\
both & of & 1 & 1 \\
of & unscorable & & 1 \\
for & unscorable & 1 & 1 \\
unscorable & of & 2 & 1 \\
of & blank & & 2 \\
for & blank & 1 & 1 \\
blank & not sure & 1 & 1 \\
not sure & not sure & & 1 \\
unscorable & unscorable & & \\
\hline
\end{tabular}


Similarly for the questions that asked for a definition of FA, 20 (40\%) respondents gave answers consistently classified as "for" learning, 12/50 (24\%) were consistently classified as "of" learning and 3/50 (6\%) were consistently classified as both. One was consistently not sure and one consistently unscorable. Again excluding blanks, 11/50 (22\%) participants gave answers classified differently between the first and second asking of the question. 2/50 (4\%) moved from "of" learning to "for" learning and one vice versa.

\subsection{Examples of a Summative Assessment Task}

\subsubsection{Semantic Analysis}

$52 \%(26 / 49)$ of respondents used the idea of exam (more specifically, 38\% (19/49) used the word "exams", $12 \%(6 / 49)$ used the word "examination" and $2 \%(1 / 49)$ used the word "test"). $12 \%(6 / 49)$ used the words "lab report" ( 1 used "report"), and in addition, the following were also used, but usually a maximum of once: "coursework", "essay", "peer marking", "questions", "assignment", "presentation". Sometimes more than one example was provided.

\subsection{2 "of" or "for" Learning}

$48 \%(24 / 49)$ of respondents gave an answer classified as "of" learning, 2\% (1/49) gave an answer classified as "for" learning and 44\% (22/49) of respondents' answers were classified as both. 6\% (3/49) were left blank and 2\% (1/49) described teaching activities, which did not answer the question.

\subsection{Examples of a Formative Assessment Task}

\subsubsection{Semantic Analysis}

$22 \%(11 / 44)$ mentioned "feedback", $16 \%$ (8/44) “exam" or "time-constrained test", $14 \%(7 / 44)$ "essay", 12\% (6/44) "presentation", 12\% (6/44) "multiple-choice questionnaire", 4\% (2/44) "coursework", 4\% (2/44) "practice" and 4\% (2/44) "draft". One referred to "peer review of student work" and "self/peer assessment of exam questions" and another to "self-marked multiple choice questionnaire", but these were the only instances of "peer" or "self".

\subsection{2 "of" or "for" Learning}

$50 \%(25 / 44)$ of respondents gave an answer classified as "of" learning, 20\% (10/44) gave an answer classified as "for" learning and 18\% (9/44) of respondents' answers were classified as both. Seven did not provide a classifiable response and often described a teaching method. Generally, however, the responses were difficult to interpret because the context of the assessment tool was in the main not supplied, many answering simply "essay", "presentation" or "exam", which were classified as "of" learning.

\subsection{Consistency of Examples (Table 2)}

For SA, 21/50 (42\%) of respondents gave both a definition and an example that were classified as "of" learning, 18/50 (36\%) gave a definition classified as "of" learning but an example classified as both, 3/50 (6\%) gave a definition classified as "for" learning but a definition classified as both, and 2/50 (4\%) gave a definition classified as both "for" and "of" learning but 
an example classified as "of" learning. Excluding the cases where no response was given, $28 / 50(56 \%)$ respondents gave examples that were not classified in the same category as the definition.

Table 2. The consistency of classified responses comparing first definitions given with examples given for both SA and FA. Numbers refer to frequency of responses that were classified according to the scheme in columns 1 and 2 ('for learning' (for), 'of learning' (of), both, unscorable, "not sure" and left blank). Only recorded permutations given.

\begin{tabular}{llll}
\hline $\begin{array}{l}\text { Classified response to } \\
\text { question } 1 \text { or } 3\end{array}$ & $\begin{array}{l}\text { Classified response to } \\
\text { question } 2 \text { or } 4\end{array}$ & $\begin{array}{l}\text { Frequency for definition } \\
\text { and example of SA }\end{array}$ & $\begin{array}{l}\text { Frequency for definition } \\
\text { and example of FA }\end{array}$ \\
\hline of & of & 21 & 16 \\
for & for & & 9 \\
both & both & 1 & 2 \\
of & for & 1 & 1 \\
for & of & 18 & 7 \\
of & both & 3 & 7 \\
for & both & 2 & 1 \\
both & of & 1 & 2 \\
of & unscorable & 1 & 2 \\
for & unscorable & & 1 \\
unscorable & of & & 1 \\
both & blank & & 1 \\
unscorable & not sure & 1 & 1 \\
not sure & not sure & 1 & \\
blank & blank & 1 & \\
unscorable & both & &
\end{tabular}

For FA, 16/50 (32\%) gave a definition and an example classified "of" learning, 9/50 (18\%) gave a definition and an example classified "for" learning, and 2/50 (4\%) gave definitions and examples classified as both "of" and "for" learning. One gave a definition classified as "of" learning, but an example classified as "for" learning, and 7/50 (14\%) vice versa. 7/50 (14\%) gave a definition classified as "for" learning and an example classified as both. Again excluding blanks, 22/50 (44\%) gave examples inconsistent with their definition.

\subsection{Formative Assessment Tasks Used with Students (Table 3)}

Almost all lecturers used FA and almost all of those used it in class, though well over half used it for homework. Approximately half the sample kept formative and summative tasks separate. 
Table 3. FA tasks used with students (numbers refer to question numbers).

\begin{tabular}{llllll}
\hline Response & $\begin{array}{l}\text { 5. FA tasks } \\
\text { used }\end{array}$ & 6. In class & 7. For homework & $\begin{array}{l}\text { 8. FA and SA } \\
\text { separate }\end{array}$ & $\begin{array}{l}\text { 9. FA and SA } \\
\text { conflated }\end{array}$ \\
\hline Yes & $94 \%(47 / 50)$ & $92 \%(46 / 50)$ & $62 \%(31 / 48)$ & $48 \%(24 / 48)$ & $38 \%(19 / 46)$ \\
No & $6 \%(3 / 50)$ & $8 \%(4 / 50)$ & $34 \%(17 / 48)$ & $34 \%(17 / 48)$ & $52 \%(26 / 46)$ \\
"Sometimes" & & & & $10 \%(5 / 48)$ & $2 \%(1 / 46)$ \\
Both & & & & $2 \%(1 / 48)$ & \\
"?" & & & & $2 \%(1 / 48)$ & \\
\hline
\end{tabular}

'Sometimes' and '?' were not in the questionnaire, but they were added by respondents.

'Both' means that both 'Yes' and 'No' were indicated or the word "both" written.

\subsection{An Example If You Conflate Summative and Formative Tasks}

Of the 38\% (19/46) that indicated they conflated summative and assessment tasks (Table 3), 28\% (14/46) gave an example. One response (2\%) concerned FA only, and one (2\%) gave two discrete examples (not conflated) of SA and FA. Three listed types of assessment, e.g. "laboratory exercises", that could conflate FA and SA and five gave explicit examples that all mentioned "feedback" and indicated that a mark was awarded. One of these indicated that a pass/fail mark was awarded on submission of work in order to encourage students to hand in work which would then be returned with feedback, fulfilling a formative purpose. In this case SA preceded FA, but two additional responses seemed to be indicating that formative preceded summative: "get students to complete part of an assignment which they can then develop into a summative assignment", and "portfolio work - two pieces of formative assessment are given then a piece of summative assessment - together it makes a portfolio which goes towards summative mark". In one case peer assessment was indicated: "students assess/mark each others' formative assessment tasks".

\subsection{How Is Formative Work Related to Summative Work?}

Question 15 asked "Is formative work related to summative work?", and if the answer was "No", then logically there would be no answer required for question 16 which asked, "If yes, how is it related?" $28 \%(14 / 50)$ did not answer question 16, and of those only $16 \%(8 / 50)$ replied "No" to question 15; 4\% (2/50) were blank for both questions, 2\% (1/50) replied "Sometimes" to question 15, and 6\% (3/50) left question 16 blank but said "Yes" to question 15 . For question $16,32 \%(14 / 50)$ responded that formatively assessed work led to summative work and 4\% (2/50) noted the contrary, that summative work led to FA.

Of the $36 \%(18 / 50)$ remaining there are some identifiable themes, although it is not always evident how FA and SA link to each other. 8\% (4/50) linked (presumably the use of FA) to learning in some way. 22\% (11/50) stated that FA and SA are similar in some way, though that was expressed as a long list of different things! 4\% (2/50) made a formal versus informal distinction, $4 \%(2 / 50)$ found the similarity in tasks, and all the other 'similarities' provided one example (i.e. $2 \%(1 / 50)$ ) of the following, "broad versus specific", "skills", "own time", "same time", "topic", "concepts" and finally "both are assessment". 


\subsection{Information Given to Students on Formative Assessment Tasks (Table 4)}

$78 \%$ of lecturers inform students that the task is FA and almost all of those explain how it is formative. More lecturers mark the work than grade it, and most $(70 \%)$ thought that FA is related to the SA tasks.

Table 4. Information given to students on FA tasks (numbers refer to question numbers)

\begin{tabular}{llllll}
\hline Response & $\begin{array}{l}\text { 11. Tell } \\
\text { students task } \\
\text { is FA }\end{array}$ & $\begin{array}{l}\text { 12. Explain } \\
\text { how task is } \\
\text { FA }\end{array}$ & $\begin{array}{l}\text { 13. Is formative } \\
\text { work marked? }\end{array}$ & $\begin{array}{l}\text { 14. Is formative } \\
\text { work graded? }\end{array}$ & $\begin{array}{l}\text { 15. Is formative work } \\
\text { related to summative } \\
\text { work? }\end{array}$ \\
\hline Yes & $78 \%(39 / 49)$ & $74 \%(37 / 48)$ & $66 \%(33 / 49)$ & $48 \%(24 / 49)$ & $70 \%(35 / 48)$ \\
No & $18 \%(9 / 49)$ & $22 \%(11 / 48)$ & $32 \%(16 / 49)$ & $48 \%(24 / 49)$ & $18 \%(9 / 48)$ \\
"Sometimes" & $2 \%(1 / 49)$ & & & & $6 \%(3 / 48)$ \\
Both & & & & $2 \%(1 / 49)$ & $2 \%(1 / 48)$ \\
\hline
\end{tabular}

\section{Discussion}

In defining SA, more than half the science lecturers did not link to the semantic meaning, although in the literature both grade and final are often interlinked (Hargreaves 2005; Taras 2008b). Most lecturers recognised SA as linked to the assessment "of" learning, which seems to signal that the discourse differentiating "of" and "for" learning has filtered into science lecturers' understanding.

Although feedback is the central component of the accepted definition of FA (Sadler, 1989; Taras, 2009; Black \& Wiliam, 2009), this notion appears to have been accepted by only about one-third of science lecturers. That about the same number associated FA with "of" learning, going against all discourses and the literature, indicates an anomaly between the semantic meaning, the link to feedback and to the concept "of" learning.

Completing the questionnaire had little impact on understanding since in general science lecturers were consistent between the first and second definitions of both SA and FA. This might at least demonstrate the presence of some form of theoretical framework into which definitions are fitted, though 12 lecturers consistently classified FA as "of" learning suggesting a flawed framework. Nevertheless, across SA and FA about one-fifth changed their opinion and for these it appears that a framework does not exist. That two respondents shifted from "for" to "of" for SA and another two from "of" to "for" for FA might suggest that the completion of the questionnaire has stimulated and perhaps consolidated thinking about assessment. That an individual shifted from "for" to "of" for FA merely indicates confusion.

In giving an example of a SA task, a similar proportion of respondents - about half - used the idea of exam as used the idea of grade in the SA definition. However, if we include those who gave as an example "lab report", which is specific to science and is also a graded assessment, this gives a much higher total than those who gave the concept of grade in the definition of SA, but is nonetheless much smaller than respondents from education who used the idea of exam. Only about half of the science respondents followed the literature, which associates "of" with 
SA (and "for" with FA) (Stobart, 2008; Wiliam, 2007, 2009). What is interesting is that $44 \%$ of science lecturers thought SA tasks could be used for both. This may be linked to Taras's (2008b) argument that HE has a tradition of using assessments for both SA and FA, more so than the compulsory sector.

In giving an example of a FA task, about one-fifth of respondents mentioned feedback, but feedback is information - or its provision - and not an assessment task. A similar proportion reported notions of exam, normally associated with SA, hence many replies would seem inappropriate to the question. "essay", "presentation", "multiple-choice questionnaire", "coursework", "practice" and "draft" are all normally associated with FA in the literature, although technically the first four are also examples of SA tasks (Stobart, 2008; Wiliam, 2007, 2009 ) and in total they constitute $50 \%$ of responses. This $50 \%$ compares directly with the first definition of FA which classified it as "for" learning. But many of the responses could be classified as "of" learning, and this again would seem to indicate a lack of alignment in their thinking and understanding of their views on assessment and its different components. As would be expected, science lecturers seem unaware of the discourse of the compulsory sector which links FA to classroom processes (Black et al., 2003; Black \& Wiliam, 2006; Wiliam, 2009).

An examination of the consistency of examples given suggests that science lecturers are more comfortable with notions of SA, and that FA is associated with confusion to a greater degree. For both SA and FA about half of the respondents gave a definition inconsistent with an example. This is particularly worrying since it indicates a disjunction between knowledge of theory and practice: these lecturers might be aware of a theoretical framework but many are unable to translate it into practice.

Although almost all lecturers used FA and almost all of those used it in class, the problem arises as to what the figures on how FA is used actually mean or represent when the definitions and understandings of FA tasks seem to be subject to idiosyncratic interpretations. What it perhaps represents is science lecturers' willingness to carry out a process that is claimed to support their students' learning. That they are not altogether clear on what this process might be is perhaps unfortunate. Separating SA and FA could have the disadvantage of dissipating effort and not taking FA tasks seriously, particularly in HE (Taras, 2009, Taras \& Davies, 2013).

The examples of conflated summative and formative tasks did not reveal any consensus or consistency of thinking and the numbers are too small for any rationale to be attributed to differences. The literature, as noted in the 'Assessment of and for Learning' section also evidences different views on the relationships between SA and FA. There was much greater consistency in the study of education lecturers (Taras, 2008a) where most represented FA as parts of learning or feedback which contribute to the whole, which is SA, continuing the trend found in the definition of FA in the compulsory sector (Black et al., 2003; Black \& Wiliam, 2009).

The research literature is divided on the relationship between SA and FA, some definitions based on the processes and some on the functions of assessment. It is little wonder therefore 
that science lecturers are confused about the relationship between SA and FA. About a third of science lecturers thought function paramount, i.e. that that FA leads to SA.

Concerning information given to students on FA tasks, science and education lecturers are, in general, in concordance: far from all inform students that tasks are formative. This is surprising as one would expect educationalists to be more meticulous about explaining pedagogic processes. The numbers of science and education lecturers marking (i.e. correcting) the work are similar but far fewer educationalists grade it. These differences again point to the assessment literature where the work of Black and Wiliam recommends separation of SA and FA and excluding grading from FA work (Black et al., 2003). The latter is counter to the work of Sadler (1989, 1998, 2010; Scriven, 1967) who demonstrated important links between grades and understanding of level and standards, which is of critical importance to students.

The knowledge shown by science lecturers of definitions and uses is patchy at best. This begs the question of where this knowledge comes from. Non-educationalists tend to engage little with educational theory in general and assessment theory in particular. Their knowledge in the main probably comes from two sources: staff development sessions they have voluntarily or compulsorily attended, and through interaction with colleagues (in a broad sense). Some may have failed to engage with either and may have been at a loss to understand what the questionnaire was asking. Perhaps the most honest answers were given by the participant we excluded from the analysis. Given such variety in sources of knowledge it is perhaps not unexpected that we see variety in understanding. We have already noted a variety in theoretical frameworks of assessment and so it is natural that there will be variety in the emphasis placed on these frameworks by different staff developers, perhaps and even probably, at a within-institution level.

Our sample size impedes generalizability, although continued comparable and comparative research would fill this gap. Questionnaire responses are influenced by a range of subjective factors and we have assumed that respondents were honest, even though many of their responses are contradictory. Also the questionnaires were issued in different places and at different times and this could have influenced the results. Further investigation can help to address these limitations. Nonetheless, expecting staff to understand the intricate relationships and definitions of assessment when theoretical frameworks are unclear is perhaps unrealistic.

Most developments in assessment in the past decade have focused on developing good practice, with the implicit assumption that we are conversant with theory. However, this work has shown that such separation of practice from theory can have consequences for basic understandings. It may that staff operate within their own, localised and personal understanding and that their opinion is that assessment is a simple notion that they know all about. Are there pockets of beliefs in small communities of scholars? Contrariwise it is possible that, despite their perhaps varying exposures to frameworks of assessment, lecturers in this particular discipline may perceive assessment, at least its theoretical aspects, as the preserve of specialists and the specialist literature.

This research adds to an increasing body of work that highlights inconsistencies and anomalies in understandings of assessment. The sphere of 'education' in general should engage in 
meaningful and fruitful discussions of assessment issues with general goals of at least reaching some consensus on the processes, protocols and working definitions within specific contexts, i.e. a flexible framework for understanding. Most assessment issues are separated from learning and teaching issues and relegated to specialist journals, even though assessment is critical for an understanding of learning and teaching, which are more fully represented in materials that are readily accessible to higher education practitioners. Can we expect lecturers to understand assessment when the way it is presented to them is not clear? This is not to say that there cannot be debate, but until the ground-rules are agreed, how can non-educationalists be expected to engage?

\section{References}

Black, P., Harrison, C., Lee, C., Marshall, B., \& Wiliam, D. (2003). Assessment for learning Putting it into practice. Maidenhead: Open University Press.

Black, P., \& Wiliam, D. (2006). Developing a theory of formative assessment. In J. Gardner (Ed.), Assessment and learning (pp. 81-100). London: Sage.

Black, P., \& Wiliam, D. (2009). Developing the theory of formative assessment. Educational Assessment Evaluation and Accountability, 21(1), 5-31. http://dx.doi.org/10.1007/s11092-008-9068-5

Broadfoot, P., \& Black, P. (2004). Redefining assessment? The first ten years of Assessment in Education. Assessment in Education, Principles Policy and Practice, 11(1), 7-27. http://dx.doi.org/10.1080/0969594042000208976

Falchikov, N., \& Boud, D. (2007). Assessment and emotion, the impact of being assessed. In D. Boud, \& N. Falchikov (Eds), Rethinking assessment in higher education, learning for the longer term (pp. 144-155). Abingdon: Routledge.

Hargreaves, E. (2005). Assessment for learning? Thinking outside the (black) box. Cambridge Journal of Education, 35(2), 213-224. http://dx.doi.org/10.1080/03057640500146880

Harlen, W. (2006). On the Relationship Between Assessment for Formative and Summative Purposes. In J. Gardner (Ed.), Assessment and learning (pp. 103-118). London: Sage.

Knight, P. (2002). Summative Assessment in Higher Education, practices in disarray. Studies in Higher Education, 27, 275-286. http://dx.doi.org/10.1080/03075070220000662

Lindblom-Ylänne, S., Pihlajamäki, H., \& Kotkas, T. (2006). Self-, peer- and teacher-assessment of student essays. Active Learning in Higher Education, 7(1), 51-62. http://dx.doi.org/10.1177/1469787406061148

Maclellan, E. (2001). Assessment for learning, the differing perceptions of tutors and students. Assessment and Evaluation in Higher Education, 26(4), 307-18. http://dx.doi.org/10.1080/02602930120063466

Nicol, D. J., \& Macfarlane-Dick, D. (2005). Formative assessment and self-regulated learning, A model and seven principles of good feedback practice. Studies in Higher Education, 31(2), 
199-218. http://dx.doi.org/10.1080/03075070600572090

Rust, C. (2002). The impact of assessment on student learning, how can the research literature practically help to inform the development of departmental assessment strategies and learner-centred assessment practices? Active Learning in Higher Education, 3(2), 145-158. http://dx.doi.org/10.1177/1469787402003002004

Sadler, D. R. (1989). Formative assessment and the design of instructional systems. Instructional Science, 18, 145-165. http://dx.doi.org/10.1007/BF00117714

Sadler, D. R. (1998). Formative Assessment, revisiting the territory. Assessment in Education, Principles Policy and Practice, 5(1), 77-85. http://dx.doi.org/10.1080/0969595980050104

Sadler, D. R. (2010). Beyond feedback, developing student capability in complex appraisal. Assessment and Evaluation in Higher Education, 35(5), 535-550. http://dx.doi.org/10.1080/02602930903541015

Scriven, M. (1967). The Methodology of Evaluation. In R. Tyler, R. Gagne, \& M. Scriven (Eds), Perspectives on Curriculum Evaluation (pp. 39-83). Chicago: R \& McNally and Co.

Smith, C. M., \& Sodano, T. M. (2011). Integrating lecture capture as a teaching strategy to improve student presentation skills through self-assessment. Active Learning in Higher Education, 12(3), 151-162. http://dx.doi.org/10.1177/1469787411415082

Stobart, G. (2008). Testing times, the uses and abuses of assessment. New York/London: Routledge.

Taras, M. (2008a). Summative and Formative Assessment, perceptions and realities. Active Learning in Higher Education, 9(2), 172-192. http://dx.doi.org/10.1177/1469787408091655

Taras, M. (2008b). Assessment for learning, sectarian divisions of terminology and concepts. Journal of Further and Higher Education, 3.2(4), 389-397. http://dx.doi.org/10.1080/03098770802395892

Taras, M. (2009). Summative Assessment, the Missing Link for Formative Assessment. Journal of Further and Higher Education, 33(1), 57-69. http://dx.doi.org/10.1080/03098770802638671

Taras, M., \& Davies, M. S. (2013). Perceptions and realities in the functions and processes of assessment. Active Learning in Higher Education, 14, 51-61. http://dx.doi.org/10.1177/1469787412467128

Wiliam, D. (2007). Keeping learning on track, classroom assessment and the regulation of learning. In F. K. Lester (Ed.), Second handbook of mathematics teaching and learning (pp. 1053-1058). Greenwich CT: Information Age Publishing.

Wiliam, D. (2009). Assessment for Learning, Why What and How. London: Institute of Education, University of London.

Yorke, M. (2013). Surveys of 'the student experience' and the politics of feedback. In S. Merry, 


\section{IIMacrothink}

M. Price, D. Carless \& M. Taras (Eds), Reconceptualising Feedback in Higher Education. London and New York: Routledge.

\section{Appendix}

Appendix 1. Questionnaire on Summative and Formative Assessment

Where "YES -- NO" is presented, please circle your choice.

1. Give a rough definition of summative assessment.

2. Give an example of a summative assessment task.

3. Give a rough definition of formative assessment.

4. Give an example of a formative assessment task.

5. Do you use formative assessment tasks with your students? YES -- NO

6. Do you use formative assessment tasks in class? YES -- NO

7. Do you use formative assessment tasks for homework? YES -- NO

8. Do you keep summative and formative tasks separate? YES -- NO

9. Do you conflate summative and formative tasks? YES -- NO

10. If yes, give an example.

\section{If you use formative assessment with your students -}

11. Do you tell them it will be a formative assessment? YES -- NO

12. Do you explain how it will be a formative assessment? YES -- NO

13. Is formative work marked? YES -- NO

14. Is formative work graded? YES -- NO

15. Is formative work related to summative work? YES -- NO

16. If yes, how is it related?

17. Without looking back, give a definition of summative assessment.

18. Without looking back, give a definition of formative assessment.

Thank you very much for your time and brain power.

\section{Copyright Disclaimer}

Copyright reserved by the authors.

This article is an open-access article distributed under the terms and conditions of the Creative Commons Attribution license (http://creativecommons.org/licenses/by/3.0/). 